\title{
Gelişmiş ve Gelişmekte Olan Ülkelerde Ar\&Ge Harcamaları ve Ekonomik Büyüme Arasındaki İlişki: Panel Veri Analizi
}

\author{
Yağmur SA $\breve{G L A M, ~ D e p a r t m e n t ~ o f ~ E c o n o m i c s, ~ B o y a b a t ~ F a c u l t y ~ o f ~ E c o n o m i c s ~ a n d ~ A d m i n i s t r a t i v e ~ S c i e n c e s, ~}$ \\ Sinop University, Turkey; e-mail: yagmur.saglam@deu.edu.tr
}

Hüseyin Avni EGELI, Department of Economics, Faculty of Economics and Administrative Sciences, Dokuz Eylul University, Turkey; e-mail: avni.egeli@deu.edu.tr

Pınar EGELI, Department of Economics and Administrative Programs, Izmir Vocational School, Dokuz Eylul University, Turkey; e-mail: pegeli@yahoo.com

\section{The Relationship between R\&D Expenditures and Economic Growth for Some Developed and Developing Countries: A Panel Data Analysis}

\begin{abstract}
The main purpose of this paper is to investigate the relationship between research and development $(\mathrm{R} \& \mathrm{D})$ expenditures and economic growth, based on 26 some developed and developing countries (Belgium, Bulgaria, Czech Republic, Denmark, Germany, Estonia, Ireland, Greece, Spain, France, Italy, Cyprus, Hungary, Latvia, Netherland, Austria, Poland, Portugal, Romania, Slovenia, Slovakia, Finland, Sweden, United Kingdom, Iceland, Norway). For this purpose, we used endogenous growth model of Romer (1990), which claims that technological change is the major source of productivity growth in the long run. Inthiscontext, usingannualdatawhich has taken from Eurostat; an empirical model has beendeveloped in the scope of the dynamic panel data analysis forth-period 19962014. The model includes real gross domestic product per capita (GDPRC) and gross domestic expenditures on $R \& D$ as an indicator of technological change (innovation). At the empirical part, firstly heterogeneity of the variables were investigate during the Delta test (Pesaran ve Yamagata, 2008), and then the existence of dependency between cross-sectional units that make series were examined by the CADF and Hadri-Kurozumi tests. After proving cointegration between series with Westurlund ECM test; Dumitrescu-Hurlin (2012) and Emirmahmutoğlu-Köse (2011) panel causality tests were applied. According to the empirical results, in the long term there is one way causal relationship from R\&D expenditures to economic growth for some selected developed and developing countries.
\end{abstract}

Keywords

JEL Classification Codes : $\quad$ C01, C31, F21, O4, O3.

Research and Development, Economic Growth, Panel Causality Analysis.

\section{Öz}

Çalışmanın amacı ekonomik büyüme ve Ar-Ge harcamaları arasındaki nedensellik ilişkisini 26 farklı gelişmiş ve gelişmekte olan ülke için analiz etmektir. Bu çerçevede Romer'in (1990), teknolojide meydana gelen değişmelerin uzun dönemde ekonomik büyümenin verimliliğini artırdığını ifade eden içsel büyüme modelinden yola çıkılmıştır. 1996-2014 dönemi Eurostat'dan elde edilen 
yıllık veriler ile dinamik panel veri analizi bağlamında incelenmiştir. Modelde kullanılan değişkenler; kişi başına düşen reel GSYİH (GDPRC) ve teknolojik değişimi temsilen Ar-Ge harcamalarının GSYİH'dan aldığı pay şeklinde ifade edilmektedir. Ampirik kısımda ilk olarak Pesaran ve Yamagata (2008) tarafından geliştirilen Delta testi ile heterojenliğe bakılmış ve değişkenler için yatay kesit bağımlılığı incelenmiştir. Heterojenlik ve yatay kesit bağımlılığını dikkate alan CADF ile HadriKurozumi birim kök testleri uygulanmıştır. Değişkenler arasındaki eş-bütünleşik ilişkinin varlığı Westerlund Hata Düzeltme Mekanizması (ECM) testi ile bulunduktan sonra Dumetriscu-Hurlin (2012) ile Emirmahmutoğlu-Köse (2011) panel nedensellik testleri yapılmıştır. Elde edilen bulgular uzun dönemde Ar\&Ge harcamalarından ekonomik büyümeye doğru tek yönlü bir nedensellik ilişkisini ifade etmektedir.

Anahtar Sözcükler : Araştırma-Geliştirme, Ekonomik Büyüme, Panel Nedensellik Analizi.

\section{Giriş}

Uluslararası ekonomik sınırların ortadan kalkması ile birlikte oluşan küresel rekabet ortamı araştırmacıları ekonomik büyümenin kaynaklarını belirlemeye itmiştir. Çünkü ekonomi teorisine göre büyüme oranında meydana gelecek olan önemli değişiklikler ülkelerin refah seviyesini değiştirmektedir. Ülkelerin gelir düzeyi ve ekonomik büyüme rakamlarında görülen farklılaşmanın nedeni Smith’e (1994) göre sahip olunan teknoloji, nitelikli iş gücü, ekonomik ve siyasi istikrar ile mevcut doğal kaynakların eşitsizliğinden kaynaklanmaktadır. Bu nedenle, Bozkurt (2015) her bir topluluğun temel arzusu olan yüksek ekonomik büyüme oranlarına ulaşmanın anahtarının bilgi teknolojileri ve bilgiyi etkin kullanarak geliştirmek olduğunu vurgulamıştır. Hu (2015) ise, Araştırma-Geliştirme (R\&D) faaliyetleri (teknolojik gelişim) ve ekonomik büyüme arasındaki boşluğun giderek birbirine yaklaştığını belirterek, etkin ve verimli teknolojilerin varlığını sürdürülebilir büyüme ve kalkınmanın kaynağı olarak görmektedir.

Büyüme oranında meydana gelen artışın bilinen farklı kaynakları mevcuttur. Bunlar, (Guellec \& Pottelsberghe, 2001: 104):

- $\quad$ İş çevreleri tarafından yaratılan teknolojinin büyüme oranına katkısı,

- Yerel teknoloji üretimi ile kıyaslandığında yabancı teknoloji akımlarının önemi (uluslararası yayılma etkisi),

- Hükümet ve üniversite işbirliği ve araştırmalarının büyümenin verimliliğini artırmas1,

- Yerel ve yabancı kaynaklardan gelmekte olan teknolojileri firmaların içselleştirme kapasitesi,

- Yeni teknolojilerin farklı kaynaklarının zaman içerisinde nasıl evrimleştiğini anlamak,

- $\quad$ Teknolojinin farklı kaynaklarının ülke özelinde nasıl bir etki bıraktığını anlamaktır.

Yukarıda sayılan sebeplerden ötürü araştırma geliştirme faaliyetlerine yapılan harcama miktarı ve bu harcamaların milli gelirden aldığı pay giderek artmaktadır. Bor ve 
diğerleri (2010), teknoloji ve bilim alanlarına yapılan Ar-Ge yatırımları; yenilik, sermaye birikimi, beşeri kaynakların gelişimi gibi farklı kanallar yoluyla, ekonomik büyümeyi etkilemektedir. Klasik büyüme modellerinden en son geliştirilen içsel büyüme teorilerine kadar büyüme olgusu üzerine teknolojinin, doğal olarak Ar-Ge harcamalarının etkisi pek çok kez tartışılmıştır. Klasik büyüme modelleri, ekonomik büyümeyi daha çok doğal kaynak, iş gücü, sermaye birikimi gibi faktörlere dayandırarak teknolojik gelişimi büyüme olgusunun dişında tutmuştur. Teknolojik gelişmenin ekonomi üzerinde yaratabileceği etkilere değinen ilk kişi Schumpeter (1911) olmuştur. Ramsey’in (1928) çalışmasını geliştiren Post-Keynesyenler (Harrod-Domar), ekonomik büyüme artışı için yatırım ve tasarrufların rolünü vurgulamışlardır. Daha sonra Neo-klasik büyümeciler olarak tabir edilen Solow (1956) ve Swan (1956), ölçeğe göre azalan getiri varsayımı altında modelde yer alan emek ve sermaye değişkenlerinin birbiri yerine ikame edilebileceğini ifade etmişlerdir. Ekonomik büyümenin emek ve sermaye ile açıklanamayan kısmının teknolojik ilerleme sayesinde olduğunu bildikleri halde modele teknolojinin nasıl üretildiğine dair açıklayıcı bir değişken ekleyemedikleri için, teknolojiyi dışsal bir değişken olarak kabul etmişlerdir.

Schumpeter tarafından ekonomik büyümeye dâhil edilen yenilik fikri 1980 sonrası Romer (1986), Helpman-Grossman (1991), Aghion-Howitt (1992) gibi içsel büyüme teorisyenleri tarafından geliştirilmiştir. Çünkü içsel büyüme modellerinin temelinde yatan düşünce; yeniliklerin yaratılmasına harcanan kaynakların sürekliliğinin ekonomik büyüme üzerinde de sürekli bir artışa yol açmasıdır (Göçer, 2013: 218). Romer (1986/90/94) ve Lucas (1988) öncülüğünde gelişen içsel büyüme teorilerini Klasik ve Neo-Klasik büyüme modellerinden ayrıştıran en önemli nokta; ekonomik büyümenin kaynağı, model içerisine dâhil edilen sistemik unsurlardır ve teknolojik gelişme içsel kabul edilmektedir, yani sistem içerisinde gelişmektedir. Romer (1986) modeli teknolojik yenilikleri ekonomik büyümenin motoru olarak tanımlamaktadır. Teknolojik yeniliklerin kaynağı ise araştırma-geliştirme faaliyetleridir. Ayrıca Ar-Ge yatırımları; beşeri sermaye ve bilgi birikimini artırarak kalkınmaya yardım etmektedir.

İçsel büyüme modellerinin temelinde yatan ölçek ekonomilerinin etkisi şu şekilde ifade edilmektedir (Jones, 1995: 761-762):

$$
\begin{aligned}
& Y=K^{1-\alpha}\left(A L_{y}\right)^{\alpha} \\
& \frac{\dot{A}}{A}=\delta L_{A}
\end{aligned}
$$

1 nolu eşitlik üretim fonksiyonunu, 2 nolu eşitlik içsel büyüme modelini ifade etmektedir. Y çıktı, K sermaye, L emek, A ise yeni bilgi-teknoloji düzeyini belirtmektedir. Ar-Ge'ye ayrılan emek miktarı arttıkça $L_{y}$, toplam faktör verimliliğindeki $\left(\frac{\dot{A}}{A}\right) \operatorname{artıŞ}$ hızlanmakta, yani ekonomik büyüme oranı artmaktadır.

Çalışmanın amacı; teknolojik gelişim ve yeniliğin temel göstergesi olarak kabul edilen Ar-Ge harcamaları ve ekonomik büyüme arasındaki uzun dönemli nedensellik ilişkisini 26 gelişmiş ve gelişmekte olan ülke ve 1996-2014 dönemini kapsayan bir dönem 
Sağlam, Y. \& H.A. Egeli \& P. Egeli (2017), “Gelişmiş ve Gelişmekte Olan Ülkelerde Ar\&Ge Harcamaları ve Ekonomik Büyüme Arasındaki İlişki: Panel Veri Analizi”, Sosyoekonomi, Vol. 25(31), 149-165.

için panel veri ekonometrisi ile analiz etmektir. İlk olarak literatür taraması çerçevesinde ele alınan değişkenler arasındaki ilişkiye yönelik güncel ampirik çalışmalar ortaya konulmuştur. Daha sonra veri seti ve çalışmada uygulanmış olan ekonometrik yöntem açıklanmış ve elde edilen bulgular doğrultusunda sonuç kısmında genel değerlendirmelere ve politika önerilerine yer verilmiştir. Çalışma, kullanılan veri setinin güncelliği ile uygulanan testlerin yeni ve güvenilir olması bakımından diğer ampirik çalışmalara kıyasla öne çıkmakta, literatüre katkı yapmaktadır.

\section{Literatür Taraması}

Ekonomik büyüme ve Ar-Ge harcamaları arasındaki ilişkiye yer veren ampirik çalışmalara bakıldığında; kullanılan analiz yöntemi, incelenen ülke ve ülke grupları ile tercih edilen göstergelerin farklı olması nedeniyle değişkenler arasındaki ilişkinin yönü hakkında üzerinde anlaşılmış tek bir görüş yoktur. Değişkenler arasında tek yönlü, çift yönlü nedensellik ilişkisi olabildiği gibi herhangi bir nedensellik ilişkisinin bulunamadığ çalışmalar da literatürde mevcuttur.

Goel ve Ram (1994) 1960-1980 dönemini ele aldıkları çalışmalarında, toplam 52 ülke (gelişmiş ve gelişmekte olan) için Ar-Ge harcamaları ile ekonomik büyüme arasında uzun dönemde anlamlı bir ilişki bulmuşlardır. Ancak nedenselliğin yönü tespit edilememiştir. Sylwester (2001) G7 ve OECD ülkeleri için Ar-Ge harcamaları ile ekonomik büyüme arasındaki ilişkiyi analiz ettiği çalışmasında, OECD ülkeleri için değişkenler arasında herhangi bir nedensellik ilişkisi bulamamıştır. Ancak G-7 ülkelerinde endüstriyel Ar-Ge harcamaları ile ekonomik büyüme arasında pozitif yönde bir nedensellik ilişki olduğunu tesbit etmiştir. Yu-ming vd. (2007) eş-bütünleşme ve nedensellik testleri ile Çin için Ar-Ge faaliyetleri ve ekonomik büyüme arasındaki ilişkiyi araştırmışlardır. Değişkenler arasında uzun dönemde çift yönlü nedensellik ilişkisi tespit edilmiştir.

Samimi ve Alerasoul (2009), 30 gelişmekte olan ülke için 2000-2006 dönemini panel veri ekonometrisi ile test etmişlerdir. Elde edilen bulgulara göre GOÜ'de Ar-Ge harcamaları oransal olarak düşük olduğu için bu değişkenden ekonomik büyümeye doğru anlamlı bir ilişki görülmemektedir. Altın ve Kaya (2009), 1990-2005 dönemini Türkiye için analiz ettikleri çalışmalarında Ar-Ge harcamalarından ekonomik büyümeye doğru uzun dönemli bir nedensellik ilişkisi belirlemişlerdir. Kısa dönemde ise değişkenler arasında tek veya çift yönlü herhangi bir nedensellik ilişkisi bulunamamıştır.

Genç ve Atasoy (2010), 1997-2014 dönemine ait verilerle Ar-Ge harcamaları ve ekonomik büyüme arasındaki ilişkiyi 34 ülke için GMM (genelleştirilmiş ortalamalar yöntemi) ile test etmişlerdir. Elde ettikleri bulgular doğrultusunda değişkenler arasında ArGe harcamalarından ekonomik büyümeye doğru tek yönlü nedensellik ilişkisi mevcuttur. Güloğlu ve Tekin (2012), 1991-2007 dönemine ait yıllık veriler ile yüksek gelir düzeyi grubuna dâhil 13 OECD ülkesi için yenilik, ekonomik büyüme ve Ar-Ge harcamaları (ayrı ayrı ve ikişerli gruplar halinde) arasındaki ilişkiyi panel sabit etkiler ve GMM yöntemleri ile test etmişlerdir. Değişkenler arasında uzun dönemde çift yönlü bir nedensellik ilişkisinin varlığını belirlemişlerdir. Gülmez ve Yardımcıŏ̆lu (2012), 21 OECD ülkesi ve 1990-2010 
Sağlam, Y. \& H.A. Egeli \& P. Egeli (2017), "Gelişmiş ve Gelişmekte Olan Ülkelerde Ar\&Ge Harcamaları ve Ekonomik Büyüme Arasındaki İlişki: Panel Veri Analizi”, Sosyoekonomi, Vol. 25(31), 149-165.

dönemi için Pedroni ve Kao panel eş-bütünleşme testini ve regresyon katsayılarını tahminlemek amacıyla FMOLS ve DMOLS yöntemlerini tercih etmişlerdir. Ar-Ge harcamaları ve ekonomik büyüme arasında uzun dönemde genel olarak tek yönlü ve güçlü bir ilişki olduğunu, Canning Pedroni testi bulgularına dayandırarak ifade etmişlerdir.

Barcenilla ve diğerlerinin (2013), 1989-2004 dönemini 15 OECD ülkesi için analiz ettikleri çalışmalarında, Ar-Ge harcamalarını teknolojik yenilik adına vekil değişken olarak atamışlardır. GMM analizi sonrası elde ettikleri bulgular, teknolojik değişimin verimlilik artışına neden olduğunu ifade etmektedir. Göçer (2013), 1996-2012 dönemini 11 Asya ülkesi için incelediği çalışmasında yatay kesit bağımlılığını dikkate alan (Hadri-Kuruzomi, Dumitrescu-Hurlin vb.) panel veri testlerini uygulamıştır. Elde ettiği bulgular doğrultusunda gelişmekte olan ülkeler, yüksek ve sürdürülebilir bir ekonomik büyüme için katma değeri yüksek ve ileri teknoloji yoğun ürünleri üreterek ihraç etmelidir. Bunun tek yolunun da ArGe harcamalarına milli gelirden daha fazla pay ayrılması olduğunu vurgulamıştır.

Özcan ve Ar1 (2014), 15 OECD ülkesi için Ar-Ge harcamaları ve ekonomik büyüme arasındaki ilişkiyi panel FMOLS yöntemi ile tahmin etmişlerdir. 1990-2011 dönemini ele aldıkları analizlerinde tüm panel veri seti için elde ettikleri sonuç Ar-Ge harcamalarının ekonomik büyümeyi pozitif yönde etkilediğidir. Santos ve Lopes (2014), 1987-2008 dönemine yönelik 22 Avrupa Birliği ülkesini (özellikle Portekiz vurgusu yaparak) ele aldıkları çalışmada, uyguladıkları Granger nedensellik testi sonuçlarına göre Fransa ve İspanya için nedensellik ilişkisinin yönünün büyümeden Ar-Ge harcamalarına doğru ve tek yönlü olduğunu belirtmişlerdir. Ar-Ge harcamalarından büyümeye doğru olan bir ilişki ise sadece Hollanda için mevcuttur. Birleşik Krallık için ilişsinin yönü negatiftir. Analize dâhil edilmiş olan diğer ülkeler için değişkenler arasında herhangi bir nedensellik ilişkisi söz konusu değildir.

Kacprzyk ve Doryn (2014), teknolojik yenilik (Ar-Ge harcamaları) ve ekonomik büyüme arasındaki ilişkiyi ele aldıkları çalışmalarında AB-28 ülkelerini, AB-13 ve AB-15 olmak üzere iki ayrı gruba ayırarak ve genel durum itibariyle analiz etmişlerdir. 1993-2011 dönemini Barro tipi bir regresyon ile modellemişler ve açıklık değişkenini analizlerine üçüncü bir değişken olarak katmışlardır. GMM testinden elde edilen sonuçlara göre AB için tek tip bir büyüme reçetesinin mümkün olmadığını ifade etmişlerdir. Akçalı ve Şişmanoğlu (2015), yeniliğin bir göstergesi olarak kabul ettikleri Ar-Ge harcamaları ve ekonomik büyüme arasındaki ilişkiyi 1990-2013 dönemi için 19 gelişmiş ve gelişmekte olan ülke bağlamında panel veri yöntemiyle analiz etmişlerdir. Swamy’nin rassal etkiler modelinin tercih edildiği çalışmanın analiz bulguları; gelişmiş ülkelerde Ar-Ge harcamalarının milli gelirden aldıkları pay gelişmekte olanlara kıyasla daha yüksek olduğu için, Ar-Ge harcamalarının ekonomik büyüme üzerine etkisinin farklı gelişmişlik düzeyine sahip ülkeler için paralellik göstermediğini ifade etmektedir.

Inekwe (2015), gelişmekte olan 66 ülkeyi kapsayan çalışmasında Ar-Ge harcamaları ve ekonomik büyüme arasındaki ilişkiyi GMM yöntemi ile analiz etmiştir. Yıllık veriler ile 2000-2009 dönemini beş farklı periyotta incelediği çalışmasından elde ettiği bulgular doğrultusunda Ar-Ge harcamalarının ekonomik büyüme üzerine etkisi düşük gelir grubuna 
giren ülkelerde anlamsız iken, üst orta gelir grubuna dâhil olan ülkelerde pozitif olarak görülmüştür; ancak uzun ve kısa dönemde bu etkiler farklılık göstermektedir.

\section{Veri Seti ve Yöntem}

Çalışmanın amacı ekonomik büyüme ve Ar-Ge harcamaları arasındaki nedensellik ilişkisini 26 farklı gelişmiş ve gelişmekte olan ülke için test etmektir. $\mathrm{Bu}$ ülkeler şu şekildedir; Belçika, Bulgaristan, Çek Cumhuriyeti, Danimarka, Almanya, Estonya, İrlanda, Yunanistan, İspanya, Fransa, İtalya, Kıbrıs, Macaristan, Letonya, Hollanda, Avusturya, Polonya, Portekiz, Slovenya, Slovakya, Romanya, Finlandiya, İsveç, Birleşik Krallık, İzlanda ve Norveç. Bu nedenle 1996-2014 dönemi büyüme ve Ar-Ge harcamalarına ait yıllık veriler ile panel veri analizi kapsamında ampirik bir model oluşturulmuştur. Oluşturulan ampirik ve iktisadi model aşağıdaki gibidir:

$$
\begin{aligned}
& G D P R C=f(A r G e) \\
& G D P R C_{i t}=a_{i}+A r G e_{i t}+\varepsilon_{t}
\end{aligned}
$$

GDPRC: ekonomik büyüme (kişi başına düşen reel GSYİH oranı),

ArGe: teknolojik değişimi (Araştırma Geliştirme Harcamalarının GSYİH’dan aldığı pay)

temsil etmektedir.

Uygulama kullanılan veri seti Eurostat veri tabanından elde edilen yıllık veriler ile oluşturulmuştur. Panel veri analizi kapsamında oluşturulan ampirik modelin tahmininde Eviews 8.0 ve Gauss 10.0 paket programları kullanılmıştır. Baltagi’ye göre (2005), panel veri analizi ekonomik birimlere ait zaman serisi gözlemlerinin yatay kesit formunda bir araya getirilerek ekonomik davranış ve ilişkilerinin modellenmesidir. Yatay kesit ve zaman serisi olmak üzere iki boyutu olan bu yapıda tahminciler için kullanılan temel eşitlik şu şekildedir:

$$
y_{i t}=\propto_{i}+\beta_{i t}+u_{i t}
$$

$i$ ekonomik karar birimlerini yani yatay kesit sayısını ve $t$ zaman boyutunu ifade etmektedir. $\propto_{i}$ sabit (constant) olup, yatay kesit ve zaman boyutuna ait tahminlerin bireysel etkilerini içermektedir (Baltagi, 2005: 6).

Cameron ve Trivedi (2005), panel veri analizi zaman içerisinde yatay kesit birimlerinde meydana gelen değişimlerin birlikte incelenmesine imkân tanımaktadır. Bu nedenle ülkelerarası karşılaştırmalı analizlerde panel veri ekonometrisinden sık bir şekilde faydalanılmaktadir.

\section{Uygulama Bulguları}

Panel veri analizlerinde; veri setleri hem yatay kesit hem de zaman serisi boyutuna sahip olduğu için belirli bir zaman dilimi içerisinde birbirleri üzerine etkilerinin olmadığını 
veya zaman serisine gelecek bir şokun yatay kesit birimlerini aynı dereceden etkilediğini varsaymak (homojenite varsayımı) mantıklı değildir. Bunun için değişkenlere ilk olarak Pesaran ve Yamagata (2008) tarafından geliştirilen Delta testi yapılmıştır. Delta testi istatistikleri aşağıda belirtildiği gibi hesaplanmaktadır (Pesaran \& Yamagata, 2008: 56; Göçer, 2013: 229):

$$
\begin{aligned}
& \tilde{\Delta}=\sqrt{N} \frac{N^{-1} \check{S}-k}{\sqrt{2 k}} \\
& \tilde{\Delta}_{a d j}=\frac{\sqrt{N} N^{-1} \check{S}-k}{\sqrt{\operatorname{Var}(T, k)}}
\end{aligned}
$$

$\tilde{\Delta}$ : Küçük örneklemler için delta test istatistiğini,

$\tilde{\Delta}_{a d j}$ : Büyük örneklemler için uyarlanmış delta test istatistiğini ifade etmektedir.

6 ve 7 numaralı denklemlerde $\mathrm{N}$ gözlem sayısını, (S) Swamy test istatistiğini, k açıklayıcı değişken sayısını ve $\operatorname{Var}(T, k)$ ise varyansı belirtmektedir. Delta testine ait boş hipotez ve alternatif hipotezler aşağıdaki gibidir (Pesaran \& Yamagata, 2008: 57-58).

$$
\begin{aligned}
& H_{o}: \beta_{1}=\beta_{2}=\cdots=\beta_{n}=\beta\left(\text { tüm } \beta_{i}{ }^{\prime} \text { ler için }\right) \\
& H_{1}: \beta_{1}=\beta_{2}=\cdots \neq \beta_{n}=\beta(\text { en az bir } i \text { için })
\end{aligned}
$$

Tablo: 1

Delta Testi Sonuçları

\begin{tabular}{lcc}
\hline Delta Testi & Test İstatistiği & Prob. \\
\hline$\hat{\hat{\Delta}}$ & 11.638 & $0.000^{*}$ \\
$\hat{\Delta}_{\text {adj }}$ & 12.623 & $0.000^{*}$ \\
\hline *simgesi \%5 düzeyinde istatistiki olarak anlamlllı̆̆ ifade etmektedir.
\end{tabular}

Tablo 1'e göre modeldeki değişkenler heterojendir. Çünkü boş hipotez reddedilmektedir. Delta testi ile homojen olmadıkları belirlenen değişkenler için yatay kesit bağımsızlığının araştırılması gerekmektedir. Çünkü seriye gelecek olan bir şok tüm yatay kesit birimlerini aynı derecede etkilememektedir. Bunun için Pesaran hem $N$ hem de T'nin büyük olduğu durumlar için $C D_{L M}$ olarak adlandırılan test istatistiğini türetmiştir (Pesaran, 2004: 4) ve $C D_{L M}$ testinin gücünü attırmak için 2008 yılında diğer araştırmacılar ile birlikte bu testi geliştirmişlerdir (Pesaran vd., 2008: 106).

$$
\begin{aligned}
& \Delta Y_{i t}=a_{i}+b_{i} Y_{i, t-1}+\sum_{j=1}^{p_{i}} c_{i j} \Delta Y_{i, t-j}+d_{i} t+h_{i} \bar{Y}_{t-1}+\sum_{j=0}^{p_{i}} \eta_{\ddot{\mathrm{u}}} \Delta Y_{i, t-j}+\varepsilon_{i, t} \\
& C D_{L M}=\sqrt{\frac{1}{N(N-1)}} \sum_{i=j}^{N-1} \sum_{J=i+1}^{N}\left(T \hat{p}_{i j}^{2}-1\right) \sim N(0,1)
\end{aligned}
$$

8 numaralı denklemde $\alpha$ ortak zaman etkisini, $b, c, d$ ve $h$ değişkenlere ait tahmin edilmiş regresyon katsayılarını, denklemde yer alan $t$ trendi, $p_{i}$ ise yatay kesit birimlerine göre en uzun gecikme sayısını ifade etmektedir. Kalıntılar arasında az ya da çok eş anlı bir 
ilişkinin olması gerekmektedir. Bu ilişkinin istatistiksel olarak anlamlılığı Breusch ve Pagan (1980) LM testi ile sınanmaktadır. $C D_{L M}$ test istatistiği aşağıdaki gibi ifade edilmektedir (Pesaran, 2004: 4; Güloğlu \& İspir, 2009: 4):

$$
C D_{L M}=T \sum_{i=j}^{N-1} \sum_{j=i+1}^{N} \hat{p}_{i j}^{2} \sim \chi_{N(N-1) / 2}^{2}
$$

$H_{0}: \rho_{i j}=\rho_{j i}=\operatorname{cor}\left(u_{i t}, u_{j t}\right)=0, \quad i \neq j$, yatay kesit birimleri arasında bağımlılık olmadığını iddia eden hipotez test edilmektedir. Bu test ile amaçlanan, En Küçük Kareler (EKK) yöntemi ile tahmin edilen her bir denklemden elde edilen kalıntılar $\left(p_{i j}\right)$ arasında korelasyon olmadığını göstermektir. Elde edilen bulgular aşağıdaki gibidir:

\section{Tablo: 2}

Değișkenler İçin Yatay Kesit Bağımsızlığı Testi

\begin{tabular}{lcccc}
\hline Sabitli Model & GDPRC & Ar-Ge & \\
& T-ist. & Prob. & T-ist. & Prob. \\
\hline$C D_{L M}(\mathrm{BP}, 1980)$ & 216.381 & 0.011 & 219.587 & $0.007^{*}$ \\
$C D_{L M}($ Pesaran, 2004) & 2.454 & 0.007 & 2.627 & $0.004^{*}$ \\
\hline * simgesi $\% 5$ dïzeyinde istatistiki olarak anlamlılığ ifade etmektedir. & &
\end{tabular}

Tablo 2'de yer alan sonuçlara göre her iki değişken için yatay kesit bağımsızlı̆̆ını ifade eden boş hipotez reddedilmektedir. Çünkü değişkenler için hesaplanmış olan olasılık değerleri istatistiki olarak anlamlıdır. Panel veri setini oluşturan yatay kesit birimleri arasında bağımlılık vardır.

Panel eş-bütünleşme testine geçmeden önce, yatay kesit bağımlılığı ile heterojen yapıyı dikkate alan ve ikinci nesil olarak tabir edilen birim kök testleri uygulanmalıdır. John Taylor (1989), birim kök içeren serilerde şoklar ve yapısal kırılmaların kalıcı bir etki bıraktığını ifade etmektedir. Geleneksel görüşün aksine seriye gelen dışsal veya içsel bir şoktan sonra zaman serisinin ortalaması ve varyansı eski seyrine geri dönmemektedir. Panel veri setinin yapısına uygun olarak Pesaran (2007) tarafından geliştirilen $C A D F$-Yatay Kesite Uyarlanmış Dicky-Fuller ve Hadri-Kurozumi (2012) birim kök testleri değişkenler için tek tek yapılmıştır. $383)$ :

$C A D F$ testi aşağıdaki regresyonun tahminine dayalıdır (Güloğlu \& İvrendi, 2010:

$$
\Delta Y_{i t}=\alpha_{i}+b_{i} y_{i, t-1}+\sum_{j=1}^{\rho_{i}} c_{i j} \Delta Y_{i, t-j}+d_{i} t+h_{i} \bar{y}_{i, t-j}+\sum_{j=0}^{\rho_{i}} \eta_{\ddot{u}} \Delta \bar{y}_{i, t-j}+\varepsilon_{i, t}
$$

Seri durağandır, boş hipotezi altında gözlem sayısı $N \rightarrow \infty$ giderken ve ortak öğe olan $\bar{y}_{t} \neq 0$ ile kendisinin gecikmeli değerleri olan $\Delta \bar{y}_{t}$ 'nin birbirine yaklaştırılabileceği ifade edilmektedir. Burada esas amaç, bu yöntem ile her bir yatay kesit için hata terimi $u_{i t}$ 'deki oto-korelasyonu dikkate almaktır. Katsayılar için elde edilen t-istatistikleri, Pesaran (2007) tablo değerleri ile karşılaştırılarak karar verilmektedir. $C A D F$ testi ile gözlem sayısının zaman boyutundan büyük veya küçük olması durumunda dahi geçerli sonuçlar elde 
edilmektedir. CIPS istatistiği, her bir yatay kesit birimi için hesaplanmış olan t-istatistik değerlerinin ortalamasını ifade etmektedir.

Tablo: 3

CADF Testi Sonuçları

\begin{tabular}{|c|c|c|c|c|}
\hline \multirow{2}{*}{$\begin{array}{c}\text { Değişkenler } \\
\text { Ülkeler }\end{array}$} & \multicolumn{2}{|c|}{ GDPRC } & \multicolumn{2}{|c|}{ Ar-Ge } \\
\hline & $\begin{array}{c}\text { Düzey } \\
\text { Sabit ve trend }\end{array}$ & $\begin{array}{l}\text { Birinci Farkı } \\
\text { Sabit ve trend }\end{array}$ & $\begin{array}{c}\text { Düzey } \\
\text { Sabit ve trend }\end{array}$ & $\begin{array}{l}\text { Birinci Farkı } \\
\text { Sabit ve trend }\end{array}$ \\
\hline Belçika & -3.228 & -3.194 & -1.524 & -2.046 \\
\hline Bulgaristan & -3.221 & -2.999 & -2.129 & -2.156 \\
\hline Çek Cum. & -3.859 & $-5.749 * *$ & -2.719 & -4.071 \\
\hline Danimarka & -3.836 & $-5.861 * *$ & -2.802 & -4.211 \\
\hline Almanya & -3.228 & $-6.733 * *$ & -2.267 & -3.361 \\
\hline Estonya & -3.180 & $-6.508 * *$ & -3.113 & -4.994 \\
\hline İrlanda & -3.094 & -4.080 & -3.329 & -4.024 \\
\hline Yunanistan & -2.986 & -4.009 & -2.815 & $-5.977 * *$ \\
\hline İspanya & -3.728 & $-5.637 * *$ & -2.084 & -4.532 \\
\hline Fransa & -3.830 & $-5.699 * *$ & -1.899 & -2.557 \\
\hline İtalya & -3.140 & $-5.566^{* *} *$ & -2.826 & -3.519 \\
\hline Kıbris & -3.204 & $-5.625 * *$ & -2.095 & -4.073 \\
\hline Litvanya & -3.030 & $-6.952 * *$ & -2.396 & -4.225 \\
\hline Macaristan & -2.858 & $-6.783 * *$ & -2.174 & -3.568 \\
\hline Hollanda & -2.395 & -4.590 & -3.336 & -3.697 \\
\hline Avusturya & -2.606 & -4.647 & -3.114 & $-5.701 * *$ \\
\hline Polonya & -2.729 & $-6.616 * *$ & -2.761 & -3.498 \\
\hline Portekiz & -2.713 & $-6.578 * *$ & -2.090 & -4.720 \\
\hline Romanya & -2.976 & -3.969 & -2.751 & -3.591 \\
\hline Slovenya & -2.978 & -4.003 & -3.587 & $-5.083 * *$ \\
\hline Slovakya & -4.321 & -4.195 & -2.919 & -4.998 \\
\hline Finlandiya & -4.340 & -4.228 & -3.443 & -4.738 \\
\hline İsviçre & -4.679 & -4.114 & -2.683 & -3.840 \\
\hline Britanya & -4.703 & -3.984 & -2.530 & -4.123 \\
\hline İzlanda & -3.955 & -4.868 & -2.633 & -3.819 \\
\hline Norveç & -3.999 & -4.610 & -2.431 & -3.306 \\
\hline CIPS & -3.416 & -5.069 & $-2.646^{*}$ & -4.017 \\
\hline
\end{tabular}

* simgesi CIPS için \%5 ve ** simgesi CADF test istatistikleri için \%1 düzeyinde istatistiki olarak anlamlllı̆̆ ifade etmektedir.

Maksimum gecikme uzunluğu 4 olarak alınmış ve optimal gecikme uzunlukları, Schwarz bilgi kriterine göre belirlenmiştir. CADF test istatistiği kritik değerleri, sabit ve trendli modelde -4.97 (\%1), -4.01 (\%5) ve -3.56 (\%10) (Pesaran 2007, tablo I(c), s.276)' da yer almaktadır. Panel istatistiği kritik değerleri, sabit ve trendli modelde -2.83 (\%1), -2.67 (\%5) ve -2.63 (\%10) (Pesaran 2007, tablo II(c), s.281)'de yer almaktadır. Panel istatistiği (CIPS), CADF istatistiklerinin ortalamasıdır. Tablo 3'e göre değişkenler düzeyde birim kök içermekte ve birinci farkları alındıktan sonra durağan hale gelmektedirler.

Hadri-Kuruzomi birim kök testi; KPSS testinin panel veri setleri için uyarlanmış halidir ve Pesaran (2007)'den yola çıkılarak geliştirilmiştir. KPSS testinin boş hipotez ve alternatifi yer değiştirmektedir. $\mathrm{Bu}$ test için iki tür test istatistiği hesaplanmaktadır. Bunlar $Z_{A}^{S P C}$ ve $Z_{A}^{L A}$ 'dir. Her ikisinin de sonsuza yakınsarken normal dağılıma sahip oldukları varsayılmaktadır. Böylece $C A D F$ 'nin güçsüz kaldığı durumlarda dahi sahte birim köke 
sebebiyet verilmemesi için uygulanmakta olan bir sağlama testi niteliğindedir. Elde edilen bulgular aşağıdaki tabloda verilmiştir. Testin tahminlediği model aşağıdaki gibidir (Hadri \& Kurozumi, 2012: 31):

$$
\begin{aligned}
& y_{i t}=z^{\prime}{ }_{t} \delta_{i}+f_{t} \gamma_{i}+\varepsilon_{i t}, \\
& \varepsilon_{i t}=\emptyset_{i p} \varepsilon_{i t-1}+\cdots+\emptyset_{i 1} \varepsilon_{i t-p}+v_{i t}
\end{aligned}
$$

$i=1, \ldots, N$ ve $t=1, \ldots, T$ iken $z_{t}$ deterministiktir, hesaplanabilir ve bağıml değişkendeki değişimi açıklayabilmektedir. Testin iddia ettiği boş hipotez, birinci nesil birim kök testlerinin tersine serinin durağan olmadığını iddia etmektedir. $O$ halde boş ve alternatif hipotez şu şekilde ifade edilmektedir (Hadri \& Kurozumi, 2012: 32):

Tablo: 4

\begin{tabular}{|c|c|c|c|c|}
\hline \multirow[b]{2}{*}{ Düzey } & \multicolumn{2}{|l|}{ Sabit } & \multicolumn{2}{|c|}{ Sabit ve Trend } \\
\hline & T-ist. & p-değeri & T-ist. & p-değeri \\
\hline \multicolumn{5}{|l|}{ GDPRC } \\
\hline ZA_spc & 1.4810 & 0.0693 & 0.9077 & 0.1820 \\
\hline ZA_la & 0.8432 & 0.1996 & 2.1171 & $0.0171^{*}$ \\
\hline \multicolumn{5}{|l|}{$A r \& G e$} \\
\hline ZA_spc & 3.6870 & $0.0001 *$ & 1.7075 & 0.0439 \\
\hline ZA_la & 1.9937 & 0.0231 & 1.7463 & 0.0404 \\
\hline \multicolumn{5}{|c|}{ Birincifarkı } \\
\hline \multicolumn{5}{|c|}{ GDPRC } \\
\hline ZA_spc & 17.5405 & $0.0000^{*}$ & 44.5926 & $0.0000 *$ \\
\hline ZA_la & 5.6902 & $0.0000 *$ & 25.2386 & $0.0000 *$ \\
\hline \multicolumn{5}{|l|}{$A r-G e$} \\
\hline ZA_spc & 9.7993 & $0.0000^{*}$ & 25.6136 & $0.0000^{*}$ \\
\hline ZA_la & 11.4879 & $0.0000^{*}$ & 30.8703 & $0.0000^{*}$ \\
\hline
\end{tabular}

\section{Hadri-Kurozumi Testi Sonuçları}

* simgesi \%1 düzeyinde istatistiki olarak anlamlılı̆̆ ifade etmektedir.

Maksimum gecikme uzunluğu 4 olarak alınmış ve her bir yatay kesit için optimal gecikme uzunlukları, Schwarz bilgi kriterine göre belirlenmiştir. $Z A_{-} s p c$, uzun dönem varyansın; Sul ve diğerleri (2005) tarafından geliştirilen yöntemle hesaplanan panel genişletilmiş KPSS testi istatistiğidir. $Z A_{-} l a$, uzun dönem varyansın Choi (1993) ile Toda ve Yamamato (1995) yöntemiyle hesaplandığ 1 panel genişletilmiş KPSS test istatistiğidir. Tablo 4'e göre değişkenler düzeyde birim kök içerirken birinci farkları alındığında durağan hale gelmektedirler. Elde edilen sonuçlar $C A D F$ testini desteklemektedir.

Panel birim kök testlerinden elde edilen bulgular yatay kesit bağımlılığı ve değişkenlerin durağanlık derecelerini dikkate alan ikinci nesil panel eş-bütünleşme testlerinin yapılması gerektiğini göstermektedir. Westerlund ECM (Hata Düzeltme Mekanizması) eş-bütünleşme testi paneli oluşturan serilerin aynı dereceden yani birinci farkı alındığında durağan olduklarını varsaymaktadır. Westerlund eş-bütünleşme testi panel test istatistikleri üç aşamada ve $H_{0}: \alpha_{i}=0$ her bir yatay kesit birimi için eş-bütünleşme ilişkisi yoktur, hipotezi altında dört ayrı test istatistiği hesaplamaktadır. Bunların ikisi grup ikisi ise 
panel istatistikleri olarak adlandırılmaktadır (Westerlund, 2007: 710-718). Ayrıca Westerlund (2007), paneli oluşturan yatay kesit birimleri arasında bağımlılık olmadığını varsaydığı için eş-bütünleşme istatistiklerinin boostrap değerleri dikkate alınarak kritik değerler ile karşılaştırılması Chang (2004) tarafından önerilmiştir. İlk aşamada model Dinamik EKK (DOLS) ile tahmin edilmektedir.

$$
\begin{aligned}
& \Delta Y_{i t}=\delta_{i} d_{t}+\lambda_{i} x_{i t-1}+\sum_{j=1}^{\rho_{i}} \alpha_{i j} \Delta Y_{i t-1}+\sum_{j=0}^{\rho_{i}} \lambda_{i} \Delta x_{i t-j+e_{t}} \\
& Y_{i t-1}=\delta_{i} d_{t}+\lambda_{i} x_{i t-1}+\sum_{j=1}^{\rho_{i}} \alpha_{i j} \Delta Y_{i t-1}+\sum_{j=0}^{\rho_{i}} \lambda_{i} \Delta x_{i t-j+\varepsilon_{t}}
\end{aligned}
$$

Daha sonra panelin tamamı için hata düzeltme katsayısı ve onun standart hatası hesaplanmaktadır. Panel eş-bütünleşme istatistikleri ise aşağıdaki şekilde hesaplanmaktadır (Westerlund, 2007):

$$
P_{t}=\frac{\alpha}{S . E(\alpha)} \sim N(0,1) \text { ve } P_{\alpha}=T_{\alpha} \sim N(0,1)
$$

Elde edilen bulgular yorumlanırken panel istatistiklerinin boostrap olasılık değerleri dikkate alınmaktadır. Sonuçlar Tablo 5'te yer almaktadır:

\begin{tabular}{|c|c|c|c|}
\hline & & t-istatistikleri & BoostrapProb. \\
\hline$g_{\tau}$ & Grup ortalamas1 & -7.688 & $0.030^{*}$ \\
\hline$g_{\alpha}$ & Grup ortalaması & -21.652 & $0.000 *$ \\
\hline$p_{\tau}$ & Panel & -5.863 & $0.030 *$ \\
\hline$p_{\alpha}$ & Panel & -21.826 & $0.000 *$ \\
\hline
\end{tabular}

Tablo: 5

\section{Westerlund ECM Testi Sonuçları}

Tablo 5'te yer alan sonuçlara göre paneli oluşturan yatay kesit birimleri arasında eşbütünleşik ilişki mevcuttur. Boostrap olasılık değerleri istatistiki olarak anlamlıdır. Boş hipotez reddedilmektedir.

Literatüre yön veren, yatay kesit bağımlılı̆̆ı ve heterojeniteyi dikkate alan panel nedensellik testlerinden birisi de Dumitrescu ve Hurlin (2012) tarafından geliştirilen yatay kesit bağımlılığı ya da bağımsızlığı durumunda etkin sonuçlara ulaşılan panel nedensellik testidir. Bu test Granger nedensellik testi ile benzerlik göstermek ile birlikte (yatay kesit birimleri için hesaplanmış olan her bir Wald test istatistiğinin ortalamasını almaktadır) eşbütünleşik ilişkinin varlığı ya da yokluğu durumunda dahi etkin sonuçlar verebilmektedir. Üç farklı test istatistiğinin (Whnc,Zhnc,Ztild) hesaplandığı bu testte boş hipotez değişkenler arasında nedensellik ilişkisinin olmadığını iddia etmektedir. Panel test istatistikleri aşağıdaki gibi hesaplanmaktadır (Dumetriscu \& Hurlin, 2012: 1-5):

$$
\begin{aligned}
& W_{N, T}^{H n c}=\frac{1}{N} \sum_{i=1}^{N} W_{i, T} \\
& Z_{N, T}^{H n c}=\sqrt{\frac{N}{2 K}}\left(W_{N, T}^{H n c}-K\right) \frac{d}{N, T \rightarrow \infty} N(0,1)
\end{aligned}
$$




$$
Z_{N, T}^{H n c}=\frac{\sqrt{N}\left[W_{N, T}^{H n c}-N^{-1} \sum_{i=1}^{N} E\left(W_{i, T}\right)\right]}{\sqrt{N^{-1} \sum_{i=1}^{N} \operatorname{Var}\left(W_{i . T}\right)}} \frac{d}{N \rightarrow \infty} N(0,1)
$$

Tablo: 6

Panel Nedensellik Testi Sonuçları

\begin{tabular}{lccc}
\hline Boş Hipotez & Test & İstatistik Değeri & Prob. \\
\hline GDPRC, Ar-Ge'nin & & & \\
Granger & Whnc & 0.585 & 0.336167 \\
nedeni değildir. & Zhnc & -1.495 & 0.130351 \\
& Ztild & -1.575 & 0.115381 \\
\hline Ar-Ge, GDPRC'nin & & & \\
Granger & Whnc & 2.406 & $0.022058^{*}$ \\
nedeni değildir. & Zhnc & 5.070 & $1.04 \mathrm{E}-06^{*}$ \\
& Ztild & 3.469 & $0.000972^{*}$ \\
\hline
\end{tabular}

* simgesi \%5 düzeyinde istatistiki olarak anlamlılı̆̆ ifade etmektedir.

Tablo 6'ya göre değişkenler arasındaki nedensellik ilişkisinin yönü Ar-Ge değişkeninden GDPRC'ye doğrudur. Çünkü elde edilen olasılık değerleri sadece nedenselliğin yönü (X'ten $Y^{\prime}$ ye) bağımsız değişkenden bağımlı değişkene doğru iken anlamlıdır. Ampirik çalışmadan elde edilen bulgular doğrultusunda ele alınan gelişmiş ve gelişmekte olan ülkeler için Araştırma-Geliştirme harcamaları yani teknolojik değişim ekonomik büyümenin nedenidir. Ayrıca her bir ülke için nedensellik ilişkisinin yönünü ayrı ayrı görmek ve ülkeler özelinde yorumlar yapabilmek için Emirmahmutoğlu-Köse (2011) tarafindan geliştirilen panel nedensellik testi uygulanmıştır. Bu testin en büyük avantajı ön testlere (birim kök ve yatay kesit bağımlılı̆̆ testleri gibi) gerek duymamasıdır. Asimptotik Granger Nedensellik kritik değerleri yerine boostrap kritik değerlerini üretip kullandığ 1 ve böylece yatay kesit bağımlılığının önüne otomatik olarak geçtiği için diğer panel nedensellik testlerine göre daha güvenilirdir. Her bir yatay kesit birimi için yorumlanabilir parametre katsayıları elde edilmektedir.

Heterojen bileşik panel modelleri için sıfır hipotezi“ $H_{0}=A_{12, i j}=0$ ” aşağıdaki model ile sınanmaktadır (Emirmahmutoğlu \& Köse, 2011: 872).

$$
z_{i, t}=\mu_{i}+A_{i 1} z_{i, t}+\cdots+A_{i k} z_{i, t-k_{i}}+\sum_{l=k_{i}}^{k_{i}+d_{\max i}} A_{i l} z_{i, t-l}+u_{i, t}
$$

$i=1,2, \ldots, N$ ve $t=1,2, \ldots, T$ iken $k_{i}+d_{\text {max }}$ maksimum gecikme sayısını ve $A_{\text {in }}$ parametre kısıtlarını ifade etmektedir. Elde edilen bulgular aşağıdaki şekilde ifade edilmektedir: 
Tablo: 7

Emirmahmutoğlu ve Köse (2011) Test Sonuçları

\begin{tabular}{|c|c|c|c|c|}
\hline Ülkeler & $\begin{array}{r}\mathbf{G D P R C} \rightarrow \mathbf{A r}-\mathbf{G} \\
W_{i}\end{array}$ & $p_{i}$ & $\begin{array}{r}\text { Ar-Ge } \rightarrow \text { GDPR } \\
W_{i}\end{array}$ & $p_{i}$ \\
\hline Belçika & 0.751 & 0.386 & 0.094 & 0.759 \\
\hline Bulgaristan & 0.735 & 0.391 & 0.364 & 0.546 \\
\hline Cek Cum. & 0.009 & 0.926 & 0.003 & 0.959 \\
\hline Danimarka & 10.626 & $0.005^{*}$ & 5.661 & $0.059^{* *}$ \\
\hline Almanya & 0.209 & 0.647 & 1.300 & 0.254 \\
\hline Estonya & 1.541 & 0.673 & 9.770 & $0.021^{*}$ \\
\hline İrlanda & 0.510 & 0.475 & 0.204 & 0.652 \\
\hline Yunanistan & 0.543 & 0.909 & 13.243 & $0.004^{*}$ \\
\hline İspanya & 0.922 & 0.337 & 0.001 & 0.972 \\
\hline Fransa & 0.020 & 0.886 & 0.310 & 0.578 \\
\hline İtalya & 4.158 & 0.125 & 1.119 & 0.572 \\
\hline Kıbris & 8.085 & $0.018^{*}$ & 1.705 & 0.426 \\
\hline Litvanya & 15.488 & $0.001 *$ & 17.350 & $0.001 *$ \\
\hline Macaristan & 0.276 & 0.599 & 0.650 & 0.420 \\
\hline Hollanda & 0.159 & 0.924 & 6.317 & $0.042 *$ \\
\hline Avusturya & 0.059 & 0.971 & 0.027 & 0.986 \\
\hline Polonya & 2.081 & 0.556 & 0.709 & 0.871 \\
\hline Portekiz & 0.022 & 0.881 & 0.348 & 0.555 \\
\hline Romanya & 4.401 & 0.111 & 2.294 & 0.318 \\
\hline Slovenya & 5.175 & $0.075^{* *}$ & 1.895 & 0.388 \\
\hline Slovakya & 0.196 & 0.658 & 1.753 & 0.186 \\
\hline Finlandiya & 3.401 & 0.334 & 1.414 & 0.702 \\
\hline İsviçre & 0.005 & 0.943 & 0.380 & 0.538 \\
\hline Britanya & 0.303 & 0.582 & 0.125 & 0.723 \\
\hline İzlanda & 1.244 & 0.537 & 3.067 & 0.216 \\
\hline Norvec & 0.365 & 0.546 & 3.086 & $0.079 * *$ \\
\hline Fisher & 64.569 & 0.113 & 76.487 & 0.015 \\
\hline
\end{tabular}

Fisher ki-kare dağgllmı yatay kesit birimleri arasındaki bağımlılığı ölçmekte zaylf kaldlğı için bu testte boostrap olasılık değerleri dikkate alınmaktadır. $W_{i}$ Wald test istatistiğini ve $p_{i}$ olasılık değerini ifade etmektedir. * simgesi $\% 5$ ve ** simgesi \%10 düzeyinde istatistiki olarak anlamllliğ ifade etmektedir.

O halde hesaplanan olasılık değerlerini dikkate alırsak; gelişmiş ülkeler olan Danimarka, Yunanistan ve Norveç için Ar-Ge harcamaları ve kişi başına düşen reel GSYİH değişkenleri arasında nedensellik ilişkisi mevcut iken, diğer ülkeler için bunu söylemek elde edilen test sonuçlarına göre mümkün değildir. Gelişmekte olan ülkeler arasından ise Estonya, Slovenya, Kıbrıs ve Litvanya için değişkenler arasında uzun dönemde bir nedensellik ilişkisinin mevcut olduğu görülmektedir. Danimarka $(0.005<0.05$ ve $0.059<0.10)$ ve Litvanya $(0.001<0.05)$ için çift yönlü nedensellik ilişkisi mevcuttur. Estonya $(0.021<0.05)$, Yunanistan $(0.004<0.05)$, Hollanda $(0.042<0.05)$ ve Norveç $(0.079<0.10)$ için ilişkinin yönü tek yönlü ve Ar-Ge harcamalarından kişi başına düşen reel GSYİH'ye doğrudur. Kıbrıs $(0.018<0.05)$ ve Slovenya $(0.075<0.10)$ için ise tam tersi durum geçerlidir. Nedensellik ilişkisinin yönü ekonomik büyümeden Ar-Ge harcamalarına doğrudur. 
Sağlam, Y. \& H.A. Egeli \& P. Egeli (2017), “Gelişmiş ve Gelişmekte Olan Ülkelerde Ar\&Ge Harcamaları ve Ekonomik Büyüme Arasındaki İlişki: Panel Veri Analizi”, Sosyoekonomi, Vol. 25(31), 149-165.

\section{Sonuç}

Sürdürülebilir ekonomik büyüme için teknolojik değişim yani Ar-Ge harcamalarına ayrılan pay önemli bir etkendir. Ayrıca gelişmiş ve gelişmekte olan ülkeler için teknoloji yoğun üretimin yarattığı katma değerin ekonomik büyümeye olan katkısı inkâr edilemez bir gerçektir. Ülkelerin dönüşüm eğrileri ancak iki şekilde eskisine göre daha iyi bir konuma gelmektedir. Bunlardan ilki teknolojik gelişim diğeri ise savaş, kıtlık vb. doğal afetler sebebiyle nüfus oranında meydana gelen büyük ve ani bir değişimdir. Günümüzde ikinci ihtimal daha uzak göründüğü için gelişmiş ve gelişmekte olan ülkeler içsel büyüme teorilerinin de açtığı yolda ilerleyerek Ar-Ge harcamalarına milli gelirden daha fazla pay ayırmakta ve bu alana yatırım yaparak ekonomik büyümeyi sürdürülebilir kılmaya çalışmaktadır. Tabi ki teknolojik değişim sürdürülebilir büyüme için tek başına yeterli değildir ancak temel gerekliliktir. Daha önce yapılmış olan ampirik çalışmalar genel olarak değişkenler arasında pozitif yönde bir ilişkinin mevcut olduğunu göstermektedir. Bu çalışmanın amacı da değişkenler arasındaki ilişkinin yönünü ele alınan ülkeler bağlamında en güncel veri seti ve ekonometrik yöntemler ile yeniden test etmek, ayrıca gelişmiş ve gelişmekte olan ülkeler bağlamında karşılaştırma yapabilmektir.

Bu nedenle 1990-2014 dönemi yıllık veriler ve panel veri ekonometrisi ile analiz edilmiştir. Çalışmadan elde edilen bulgular ele alınan ülke grubu bağlamında Ar-Ge harcamalarının ekonomik büyümenin nedeni olduğunu ifade etmektedir. Uzun dönemde değişkenler arasında Ar-Ge harcamalarından ekonomik büyümeye doğru tek yönlü bir nedensellik ilişkisi bulunmaktadır. Ülkeler tek tek değerlendirildiklerinde ise; Danimarka, Yunanistan ve Norveç gibi gelişmiş ülkeler ile Estonya, Kıbrıs, Slovenya ve Litvanya gibi bazı gelişmekte olan ülkelerde değişkenler arasında bir nedensellik ilişkisinin mevcut olduğu görülmektedir. Diğer ülkeler için değişkenler arasında herhangi bir nedensellik ilişkisi mevcut değildir.

1980 sonrası pek çok gelişmekte olan ülke ekonomisi ekonomik büyüme oranlarını artırabilmek için dişa yönelik sanayileşme politikalarına ve özellikle Ar-Ge faaliyetlerine yönelmişlerdir. Ülke ekonomilerinin içerisinden geçtiği yapısal dönüşüm sırasında bilgi ve yenilik kavramlarının üretim süreci içerisindeki önemi kavranmış ve bunun doğal bir sonucu olarak GSYİH'den yeniliğe yani Ar-Ge faaliyetlerine ayrılan pay artmıştır. Gelişmiş ülkelerin üzerinde uzun süredir önemle durduğu Ar-Ge faaliyetleri hükümet eliyle değil daha çok sanayi (özel sektör) üniversite işbirlikleri çerçevesinde gerçekleşmiş ve günümüzde de hala bu şekilde teknoparklar aracılığıyla devam etmektedir. Hükümetler ise daha çok özel sektörü yenilik konusunda teşvik edecek politik kararlar alma ve uygulama konusunda aktif bir rol üstlenmiştir.

Ancak gelişmiş ve gelişmekte olan ülkeler arasındaki kalkınma farklılıkları her alanda olduğu gibi (makro ve mikro ekonomik bağlamda) teknolojik gelişim alanında da kendisini göstermektedir. Ele alınan ülkeler bağlamında GOÜ kapsamına giren AB dönüşüm ekonomilerinin çoğunda (Estonya, Litvanya, Slovenya hariç); ekonomik büyüme ve Ar-Ge faaliyetleri arasında herhangi bir nedensellik ilişkisi bulunmamaktadır. Çünkü bu ülkeler daha çok Almanya, İtalya ve Fransa gibi gelişmiş ülkelerin özellikle otomotiv ve elektronik 
sanayinde yapmış olduğu doğrudan yatırımlar (kurulu fabrika) sayesinde teknoloji üretebilmektedir. Ancak henüz teknolojiyi içselleştirip kendi üretimlerini yapma ve ihraç etme aşamasına tam olarak geçememişlerdir. İlginç olan, elde edilen uygulama bulgularına göre Danimarka, Norveç, Yunanistan, Hollanda hariç Britanya, Fransa, İtalya, Almanya, Finlandiya, İzlanda gibi AB'nin süper güçleri için herhangi bir nedensellik ilişkisine rastlanamamış olmasıdır. Belki de Ar-Ge harcamaları tek başına ekonomik büyümenin kaynağı olmadığı için böyle bir sonuç elde edilmiş olabilir. Gelişmiş ülkelerde Ar-Ge harcamalarının milli gelirden aldıkları pay genel olarak gelişmekte olan ülkelere kıyasla daha yüksek olduğu için, Ar-Ge harcamalarının ekonomik büyüme üzerine etkisinin farklı gelişmişlik düzeyine sahip ülkeler için paralellik göstermemesi doğal bir sonuçtur. Fakat genel olarak panel nedensellik analizi bağlamında gelişmiş ve gelişmekte olan ülkeler için Ar-Ge harcamalarına milli gelirden ayrılan pay ekonomik büyümenin bir nedenidir. Bu nedenle teknolojik gelişimi ve bilgi üretimini teşvik eden politika tercihlerine ve uygulamalarına devam edilmelidir. Bu çerçevede özel sektör, üniversite ve devlet işbirliği büyük önem taşımaktadır. Gelişmekte olan ülkelerin; üretim yapısı ve doğal kaynak zenginliğine uygun yenilik alanları belirleyerek ve mevcut çalışma gücüne eğitim yolu ile (teknoloji yoğun) vasıf katarak başka ülkelerin laboratuvarı olması önlenebilir.

\section{Kaynaklar}

Aghio, P. \& P. Howitt (1992), “A Model of Growth through Creative Destruction”, Econometrica, 60(2), 323-331.

Akçalı, B.Y. \& E. Şişmaoğlu (2015), "Innovation and the Effect of Research and Development Expenditure on Growth in Some Developing and Developed Countries", Social and Behavioral Sciences, 195, 768-775.

Altın, O. \& A.A. Kaya (2009), “Türkiye'deAr-Ge Harcamaları ve Ekonomik Büyüme Arasındaki Nedensellik İlişkisininAnalizi”, Ege Akademik Bakış, 9(1), 251-259.

Barcenilla-Visús, S. \& J.M. Gómez-Sancho \& C. López-Pueyo \& M.J. Mancebón \& J. Sanaú (2013), "Technical Change, Efficiency Change and Institutions: Empirical Evidence for a Sample of OECD Countries", Economic Record, 89(285), 207-227.

Bozkurt, M. (2015), "R\&D Expenditures and Economic Growth Relationship in Turkey", International Journal of Economics and Financial Issues, 5(1), 188-198.

Breusch, T.S. \& A.R. Pagan (1980), “The Lagrange Multiplier Test and Its Application to Model Specifications in Econometrics", Review of Economic Studies, 47, 239-253.

Chang, Y. (2004), "Bootstrap Unit Root Tests in Panels with Cross-sectional Dependency", Journal of Econometrics, 120, 263-293.

Emirmahmutoğlu, F. \& N. Köse (2011), "Testing for Granger Causality in Heterogeneous Mixed Panels", Economic Modelling, 28, 870-876.

Genç, A.C. \& Y. Atasoy (2010), "The Relationship between R\&D Expenditures and Economic Growth: Panel Data Analysis", The Journal of Knowledge Economy and Knowledge Management, 5, 27-34.

Goel, R.K. \& E.P. James \& R. Rati (2008), "R\&D Expenditures and U.S. Economic Growth: A Disaggregated Approach”, Journal of Policy Modeling, 30(2), 237-250.

Göçer, İ. (2013), “Ar-Ge Harcamalarının Yüksek Teknolojili Ürün İhracatı, Dış Ticaret Dengesi ve Ekonomik Büyüme Üzerine Etkileri”, Maliye Dergisi, 165, 215-240. 
Sağlam, Y. \& H.A. Egeli \& P. Egeli (2017), “Gelişmiş ve Gelişmekte Olan Ülkelerde Ar\&Ge Harcamaları ve Ekonomik Büyüme Arasındaki İlişki: Panel Veri Analizi”, Sosyoekonomi, Vol. 25(31), 149-165.

Grossman, G.M. \& E. Helpman (1991a), Innovation and Growth in the Global Economy, Cambridge Mass: MIT Press.

Grossman, G.M. \& E. Helpman (1991b), "Quality Ladders in the Theory of Growth", The Review of Economic Studies, 58(1), 43-61.

Grossman, G.M. \& E. Helpman (1991c), "Quality Ladders and Product Cycles”, The Quarterly Journal of Economics, 106(2), 557-586.

Guellec, D. \& B. Pottelsberghe (2001), "R\&D and Productivity Growth: Panel Data Analysis of 16 OECD Countries”, OECD Economic Studies, 33(2), 103-126.

Gülmez, A. \& F. Yardımcıoğlu (2012), "OECD Ülkelerinde Ar-Ge Harcamaları ve Ekonomik Büyüme İlişkisi: Panel Eşbütünleşme ve Panel Nedensellik Analizi 1990-2010)”, Maliye Dergisi, 163, 335-353.

Güloğlu, B. \& B.R. Tekin (2012), "A Panel Causality of the Relationship among Research and Development, Innovation and Economic Growth in High Income OECD Countries", Euroasian Economic Review, 2(1), 32-47.

Güloğlu, B. \& S. İspir (2009), Yeni Gelişmeler Işığında Türkiye'de Satın Alma Gücü Paritesi Ön Savının Panel Birim Kök Sinamasl, Pamukkale Üniversitesi İ.İ.B.F. İktisat Bölümü Yayınları.

Güloğlu, B. \& M. İvrendi (2010), "Output Fluctuations: Transitory or Permanent? The Case of Latin America”, Applied Economics Letters, 17, 381-386.

Hadri, K. \& E. Kurozumi (2012), “A Simple Panel Stationarity Test in the Presence of Serial Correlation and a Common Factor", Economics Letter, 115, 31-34.

Hu, A.G. (2015), "Innovation and Economic Growth in East Asia: An Overview", Asian Economic Policy Review, 10, 19-37.

Hurlin, C. \& E. Dumitrescu (2012), "Testing for Granger Non-Causality in Heterogeneous Panels", <Economic Modelling, https://ideas.repec.org/p/hal/wpaper/halshs-00224434.html>, 25.09.2015.

Inekwe, J.N. (2015), "The Contrubution of R\&D Expenditures to Economic Growth in Developing Economies", Social Indicators Research, 124, 727-745.

Kacprzyk, A. \& W. Doryn (2014), "Innovation and Economic Growth in European Union Panel Data Analysis", Lodz Economics Working Papers, 3, 1-27.

Lucas, R.E. (1988), “On Mechanism of Economic Development”, Journal of Monetary Economics, 22(1), 3-42.

Jones, C.I. (1995), “R\&D-Based Models of Economic Growth”, Journal of Political Economy, 103(4), 759-84.

Özcan, B. \& A. Arı (2014), “Araştırma-Geliştirme Harcamaları ve Ekonomik Büyüme İlişkisi: Panel Veri Analizi”, Maliye Dergisi, 166, 39-55.

Pesaran, H.M. (2007), "A Simple Panel UnitRoot Test in the Presence of Cross Section Dependence", Journal of Applied Econometrics, 22(2), 265-312.

Pesaran, H.M. \& T. Yamagata (2008), “Testing Slope Homogeneity in Large Panels”, Journal of Econometrics, 142, 50-93.

Ramsey, F.P. (1928), “The Mathematical Theory of Saving”, The Economic Journal, 38(152), 543559.

Romer, P.M. (1986), “Increasing Returns and Long-Run Growth”, Journal of Political Economy, 94(5), 1002-1037. 
Romer, P.M. (1990), “Endogenous Technological Change”, Journal of Political Economy, 98(5), 71102.

Samimi, A.J. \& S.M. Alerasoul (2009), "R\&D and Economic Growth: New Evidence from Some Developing Countries", Australian Journal of Basic and Applied Sciences, 3 (4), 34643469.

Santos, F.J. \& M.C. Lopes (2014), "Does R\&D Matter for Economic Growth or Vice-Verca? An Application Portugal and Other European Countries", Archives of Business Research, 2(3), 1-17.

Schumpeter, J.A. (1911), The Theory of Economic Development, Jürgen Backhaus (ed.), Joseph Alois Schumpeter, Boston: Kluwer.

Solow, R.M. (1956), “A Contribution to the Theory of Economic Growth”, Quarterly Journal of Economics, 70, 65-79.

Smith, K. (1994), "New Directions in Research and Technology Policy: Identifying Key Issues", STEPS Country Report.

Swan, T.W. (1956), "Economic Growth and Capital Acumulation”, Economic Record, 32(2), 334361.

Sylwester, K. (2001), "R\&D and Economic Growth", Knowledge, Technology \& Policy, 13(4), 7184.

Taylor, J. (1989), “The Evolution of Ideas in Macroeconomics”, The Economic Record, 65, 185-189.

Toda, H.Y. \& T. Yamamoto (1995), "Statistical Inference in Vector Autoregressions with Possibly Integrated Processes", Journal of Econometrics, 66, 225-250.

Westerlund, J. (2007), “Testing for Error Correction in Panel Data”, Oxford Bulletin of Economics and Statistics, 69(6), 709-748.

Yu-ming, W. \& Z. Li \& L. Jian-xia (2007), “Co-integration and Causality between R\&D Expenditure and Economic Growth in China: 1953-2004", International Conference on Public Administration, <http://web.cenet.org.cn/upfile/113225.pdf>, 21.01.2017. 
Sağlam, Y. \& H.A. Egeli \& P. Egeli (2017), "Gelişmiş ve Gelişmekte Olan Ülkelerde Ar\&Ge Harcamaları ve Ekonomik Büyüme Arasındaki İlişki: Panel Veri Analizi”, Sosyoekonomi, Vol. 25(31), 149-165. 